\title{
Model for ensuring strategic security of the state
}

\author{
Eduard Arkhipov ${ }^{1}$, Galina Krokhicheva ${ }^{1}$, Iulia Mezentseva ${ }^{1,{ }^{*}}$ and Tatyana Sidorina ${ }^{1}$ \\ ${ }^{1}$ Don State Technical University, 1, Gagarin sq., 344010, Rostov-on-Don, Russia
}

\begin{abstract}
The article is devoted to the state strategic security ensuring study in current realities. In modern conditions the operational, tactical and strategic activities of the legal relationship subject occur in a difficult economic situation, which depends on the external and internal conditions of the legal relationship subject's life, thus, uncertainty and risks i.e. an integral part of a market economy is the most important factor influencing the relevant decisions' adoption in order to ensure the state's economic security in general and business security in particular. For the purpose of effectively ensuring the state strategic security in current realities, the authors developed and proposed a special model for ensuring the strategic security of the state, which allows taking into account the parameters of the external and internal environment with an emphasis on strategic indicators in the context of space and time, interests and priorities of legal entities and mechanisms, methods, and means of influencing them, the area of possible strategic decisions and the control itself, i.e. the resulting factor determining the creation of the platform: the result, changes in resources, terms, responsible persons, result and ensuring the strategic security of the state.
\end{abstract}

\section{Theoretical and methodological basis of the study}

The operational, tactical and strategic activities of the legal relationship subject occur in modern conditions in a difficult economic situation, which depends on the external and internal conditions of all institutional units' life, thus, uncertainty and risks i.e. an integral part of the market economy is the most important factor influencing the relevant decisions' adoption for business management, which in turn consists of leveling threats and risks and at the same time ensuring its stable development.

So, in market realities, the most important aspect of any legal relationship subject's activity is its security and dynamic development, due to the leveling of challenges, threats and risks and maximizing its utility function i.e. attractiveness, namely the property increment. Thus, in order to ensure economic security in general, it is necessary and advisable to use the relevant government management in general and business in particular, both through the activities of the control and oversight bodies, and through the adequate work of the legal entities themselves (firms, companies, institutions, organizations, enterprises etc.). This is possible by achieving simultaneous protection against both external

\footnotetext{
* Corresponding author: mezentseva.y.r@mail.ru
} 
and internal threats and risks, as well as ensuring the property stable development maximization.

In order to ensure the stable business development of any legal relationship subject, it is advisable to proceed from their development vector in Russia, which in turn is defined in the national security strategy of the Russian Federation, which in turn determines the congruence of the system goals as a whole and a specific element of this system i.e. useful interaction of business and government [1].

Thus, it is the provision of economic security that determines the stability and ability to adapt the legal relationship subject to external and internal changes, to prevent, manage and relevantly use them in order to ensure the efficient resources use and possible sustainable property growth.

The multifaceted nature of the economic security ensuring problems is caused, firstly, by the desire of institutional units to maximize their profits, and secondly, by the state's intention to create conditions under which the realization of these desires will maximize the benefits for society. So, the socio-economic systems' innovative development strategic directions determine the diversity of this interaction, thereby emphasizing its complexity and significance, as well as its expediency [2]. The interaction of all subjects of the legal relationship is also due to the specifics of their environment, namely the institutional characteristics of the economic security in the region, which in turn affects the competitive features of business in a particular region, as well as its development [3]. The importance and urgency of ensuring the economic business security is also determined by the technologies used, namely the response speed and databases, the emphasis being made on the uneven development in the regions, which leads to the fractality of ensuring economic security both in the country as a whole and in individual regions [4]. The issues of ensuring economic security are also laid down in normative legal acts, for example, the Strategy for Economic Security of the Russian Federation for the period up to 2030 defines threats and indicators of economic security of both the country as a whole and business in particular, which helps to increase the relevance of this problem [5]. The information space influence on economic security of both business and the region is also an important aspect of ensuring economic security, since the information war often provides an effective tool for the competition [6]. The Decree of the President on National Goals and Strategic Tasks of the Development of the Russian Federation for the period up to 2024 defines a development vector for the near future, which should be taken into account when carrying out any income-generating activities [7]. S.V. Novoselov and S.A. Panikhidnikov proceed from the necessity and expediency of the economic security systematic assessment, since a single element does not always reflect the picture, and the totality of interrelated elements makes it possible to have a different meaning (synergistic effect) [8]. Thus, a systematic approach to ensuring economic security should be based on a development vector and resource potential. So, the authors T.L. Sergeeva and L.E. Skripkin pointed out the necessity and expediency of the applied methodological approaches to the resource potential study, which gives an opportunity to understand what resources should be used and in what way in order to maximize their effectiveness [9]. Methodological approaches to assessing the resource potential, directly disclosed by the authors E.A. Bessonova and O.Yu. Mereshchenko, make it possible to draw the conclusions about the direct impact of changes in resources (both when they are used directly and when they decrease (theft, damage)) on economic security [10]. E.A. Dynnikov, A.N. Milyukin, applying methodological approaches to assessing the resource potential of the region, clearly demonstrated the economic security theoretical and practical aspects' interrelation in the context of changes in resources, as well as their impact on the institutional unit [11]. It is also worth noting that the resources are theoretically of equal importance both material and non-material, and in practice, the bias towards the specific resources is due to their influence on the legal relationship subject, as well as 
possible profitability. The intangible resources potential use evaluation, emphasizing their importance and significance, is devoted to the work of E.V. Mikhalkina and N.A. Kosolapova [12]. Thus, it is necessary and appropriate to use analytical approaches and methods for assessing economic security, and their diversity and application criteria are disclosed by the authors: V.A. Tsvetkov, M.N. Dudin, N.V. Lyasnikov [13]. It is worth noting that business usually has a link to a specific region, the potential of which is also necessary and appropriate to reveal in order to identify its strengths and weaknesses, as well as additional opportunities and threats [14]. Competitive advantage is also often due to the innovative development resource potential of the regional economy, which in turn affects the business development vector [15]. Based on the foregoing, it is logical to trace the relationship between the economic security of an institutional unit and the space in which it is located, as well as the resources and opportunities that they can provide business with. The fact of the need for the resources effective management and capital remains inexorable, which is advisable to do by ensuring strategic security.

\section{Results of the study and discussion}

In order to provide strategic security ensuring i.e. leveling all multifaceted challenges, threats and risks while ensuring stable development, it is logical and appropriate to consider the economic security of the state.

In consequence of the foregoing, it is advisable to propose a model developed by the authors to ensure the strategic security of the state (Figure 1).

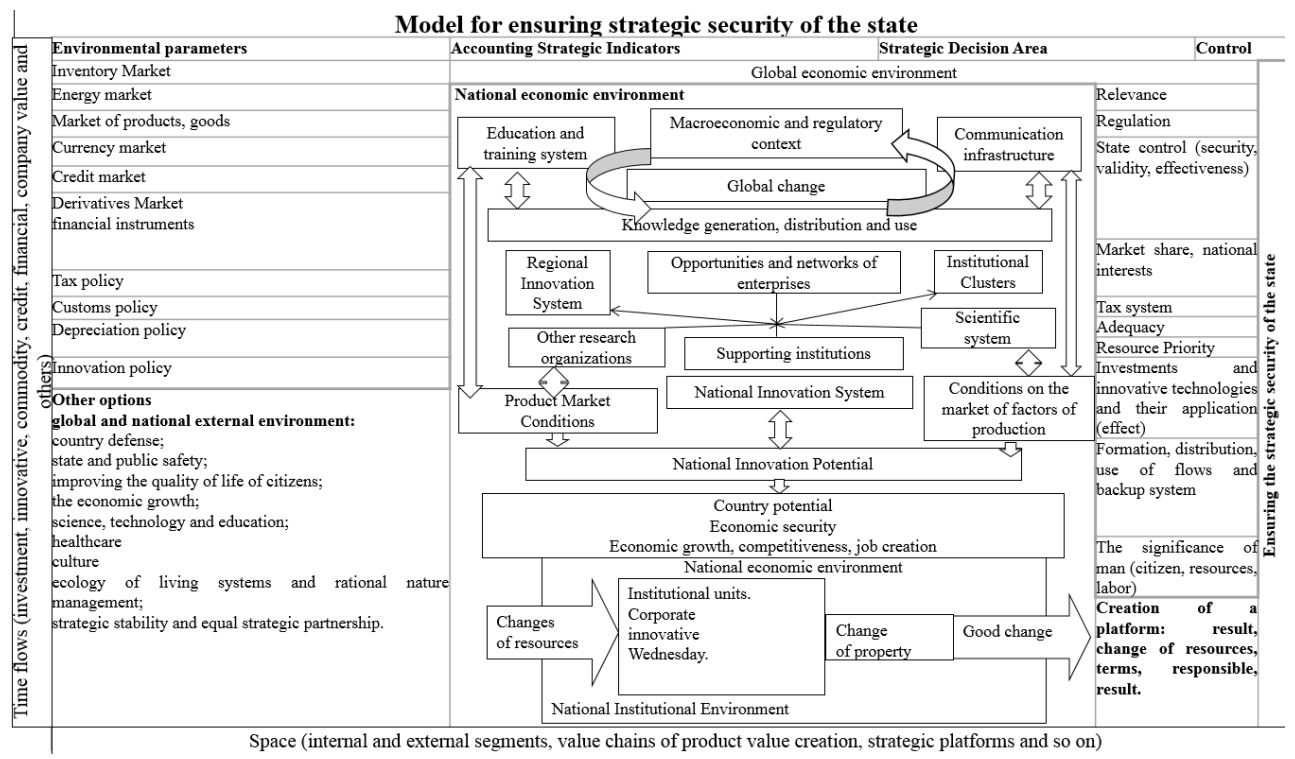

Fig. 1. Model for ensuring strategic security of the state.

The model consists of the following interconnected enlarged blocks:

The first block of the model for ensuring strategic security of the state is temporary flows i.e. time streams, i.e. investment, innovative, commodity, credit, financial, company value, etc. It clearly demonstrates the diversity of possible simultaneously carried out processes, and also emphasizes the fact that the time intervals of the processes differ, for example, their effective management helps maximize solvency (Example: terms for returning money and transferring them on credit, i.e. the ratio of the receivables and payables' terms in the context of clients, amounts and terms). 
The second block of the state strategic security model is space i.e. internal and external segments, value chains of product value creation, strategic platforms, etc. It answers the question: where something is happening i.e. in which segments, and answers the question: how they are interconnected i.e. Basel on which the whole system is built, namely, all the legal relationship subjects with an emphasis on its versatility (individuals and legal entities, employees and officials, i.e. all those who have interests and interact with the resources through their formation, distribution and use).

The third block of the model for ensuring the strategic security of the state is the parameters of the external environment that affects the country in general and individual subject of legal relationship in particular. Thus, by virtue of the regulatory legal acts and public administration adoption, the state, on the one hand, can affect the life support processes of legal entities, and on the other hand, it is also exposed to the external environment expressed by the actions of other countries, major transnational market participants, institutional investors and associations capable of affect the resource market.

The fourth block of the model for ensuring strategic security of the state is the accounting strategic indicators i.e. what is the basis for making managerial decisions, namely: a criterion (characterizes the qualitative basis of economic security in a separate direction), an indicator (determines the quantitative characteristic of this phenomenon), an indicator (in contrast to the indicator that gives only a quantitative statement, the indicator is vectoral, directional nature and also limits the limit threshold (minimum and maximum) values). Thus, accounting strategic indicators should be divided into global, national and institutional. It is also worth noting that the ensuring economic security interrelations model (Figure 2), which demonstrates the relationship of the state and the innovation environment i.e. the changes that continuously occur in market conditions with an emphasis on the IT technologies' continuous development, with this approach, the main elements of ensuring economic security are the economic opportunities to create jobs, the security of population incomes, long-term economic growth and the economy competitiveness.

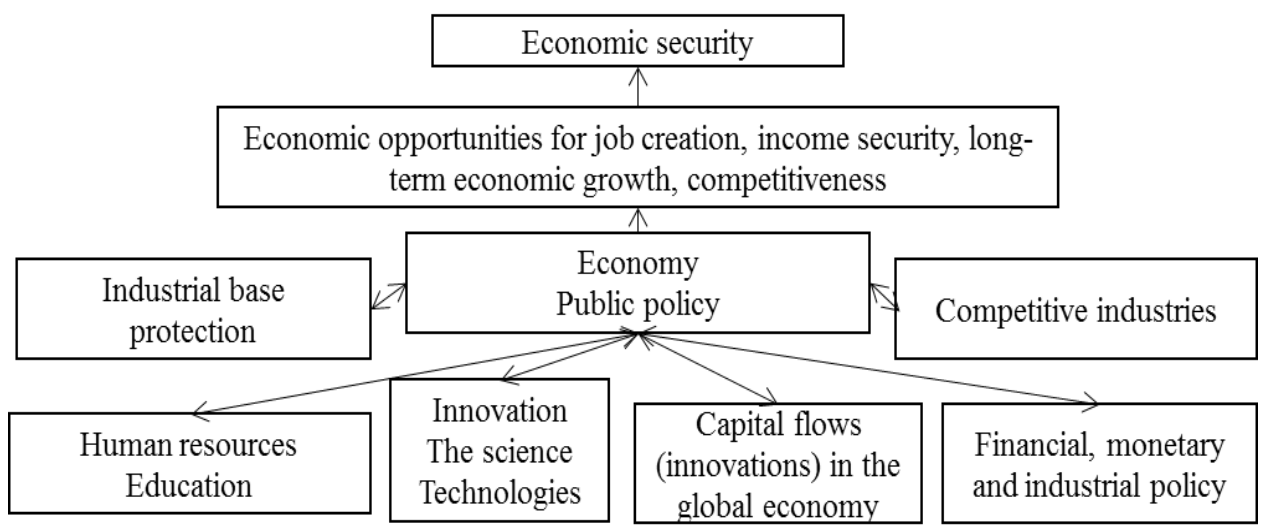

Fig. 2. Economic Security Interconnection Model.

The importance and significance of national economic security, based on knowledge, innovations, skilled labor resources, integrating the actions of all subjects of legal relationship should be considered by a special model (Figure 3).

Thus, the interaction of the national economy with the global one with an emphasis on the elements and priorities of the national economy, makes it possible to neutralize the negative external effect and ensure the stable development of the legal relationship national subjects. 
It is also worth noting the fact that there is a logic of decision-making among the institutional units (Figure 4).

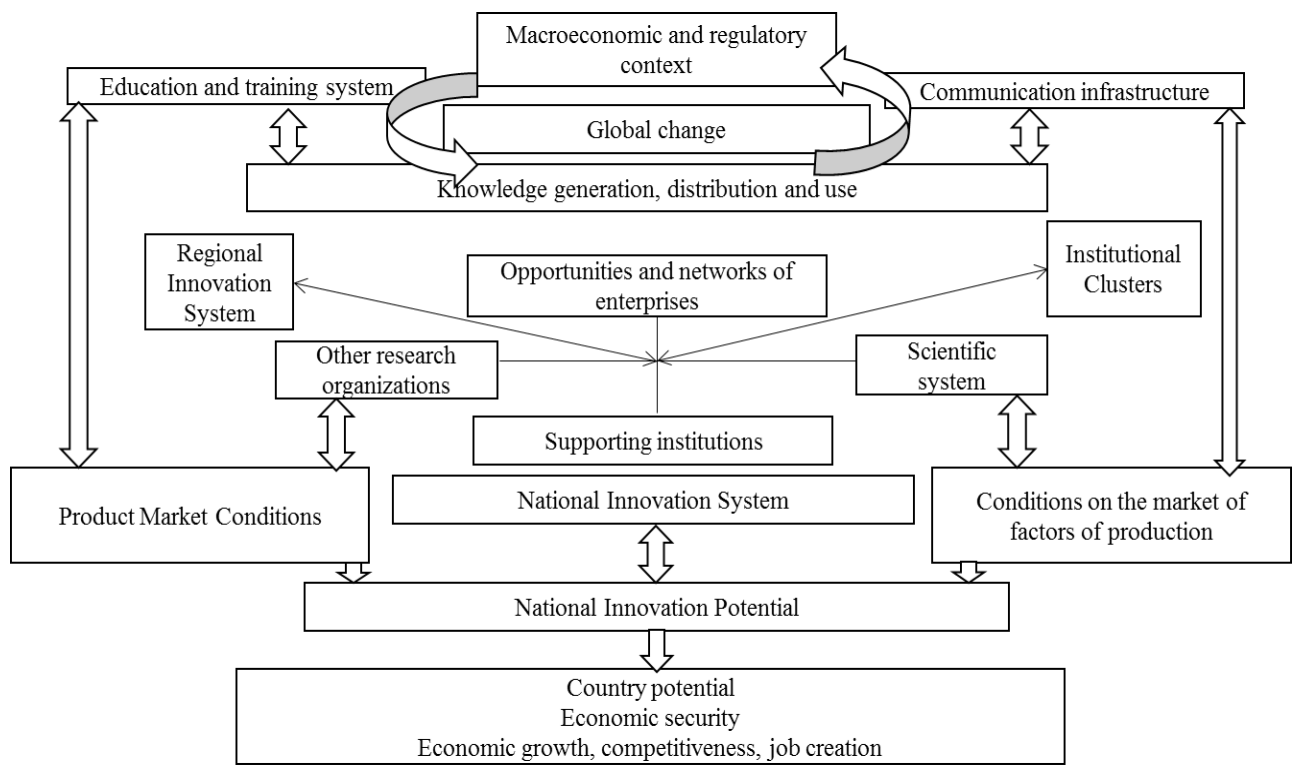

Fig. 3. The model of economic security elements' interaction.

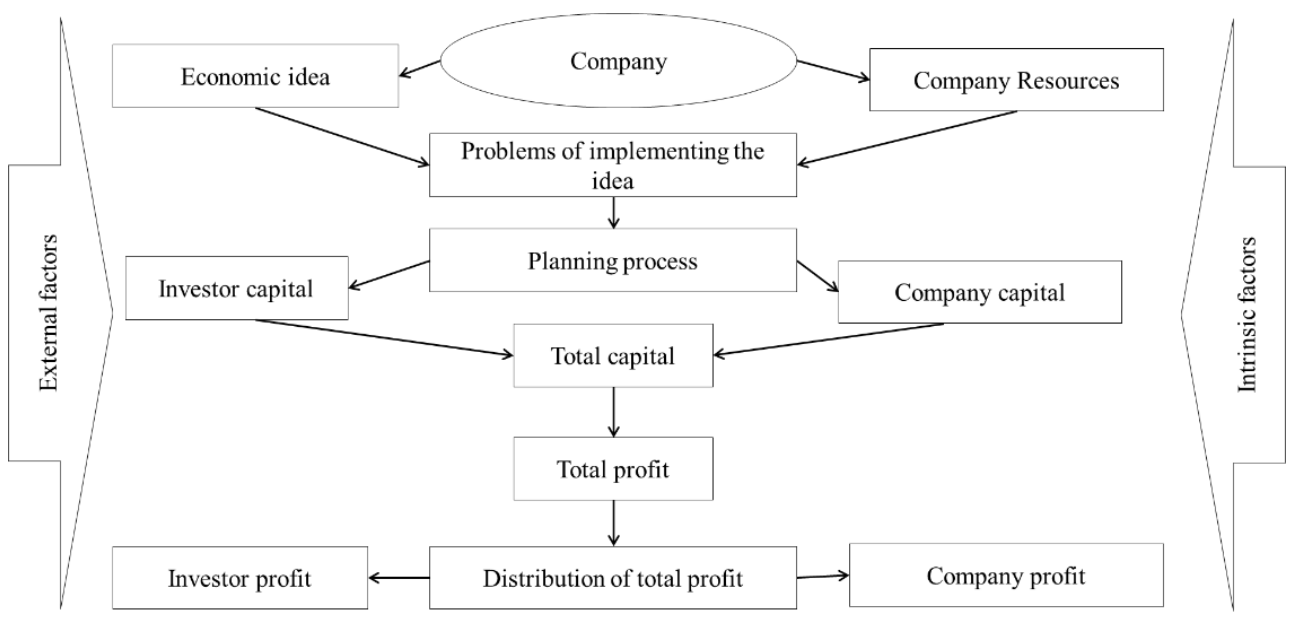

Fig. 4. A model for making operational, tactical and strategic relevant administrative decisions.

Thus, the logic of making operational, tactical and strategic relevant administrative decisions of the institutional units is focused primarily on the investors who, based on their rate of return, make the decisions on the projects and investments' profitability; on the basis of this it follows that the investors are not always interested in the development stability of a specific institutional units since the investors are often driven by a thirst for profit, including the short-term profit, therefore, the paradigm of attracting any investment with priority on foreign ones (since the foreign financial market is larger, which means there are more hypothetical development means) does not always work. It is national interests that should be prioritized when deciding on the investments' sufficiency and reasonableness, especially with foreign capital, otherwise there is risk to lose control over systemically important companies, or they will become foreign and will dictate their conditions i.e. large 
investments can lead to not always rationally used movement of funds and ideas. Basel should be the paradigm of the national market self-sufficiency for life-supporting and system-forming subjects of legal relationship, goods, services.

In their activities' implementation, all the subjects of legal relationship pursue their interests, so the interests of private companies are maximizing their profits, and the state interests are the creation of such conditions under which the benefit for the country citizens will be maximized, while protecting from the external threats and dangers. Proceeding from this, it follows that the state should put domestic policy as a priority, and foreign policy should ensure the independence and stable development of domestic policy.

So, in order to implement this idea, the "Model for ensuring the strategic development of the Russian economy", consisting of the following subunits, was developed and proposed (Figure 5):

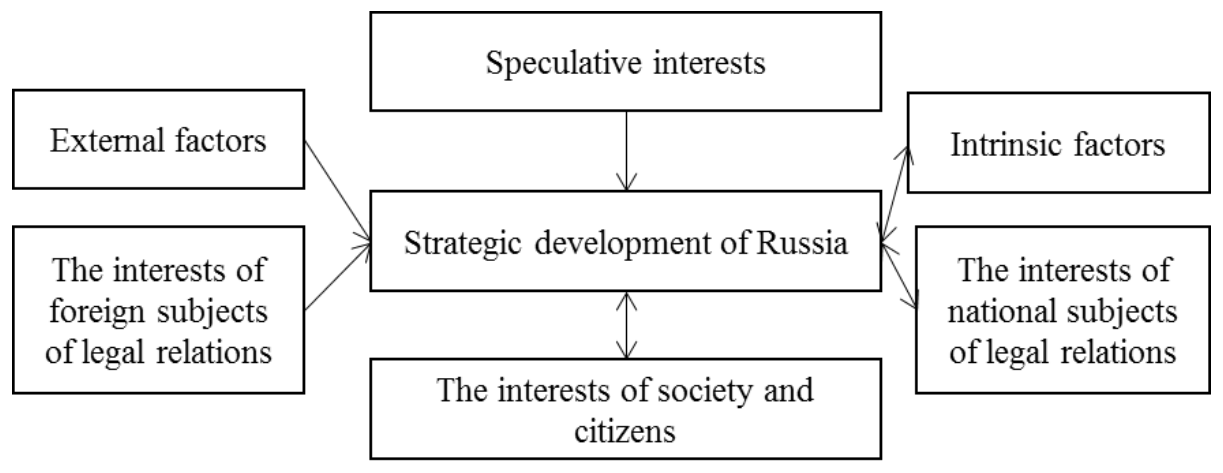

Fig. 5. Model for the strategic development ensuring of the Russian economy.

The first sub-block of the model for ensuring the strategic development of the Russian economy is represented by the external factors, which are some variables that affect Russia, these include: the development level of economies, technologies, innovations, etc. External factors are a given coming from outside to the territory or relative to the interests of Russia, therefore, it is possible to work with them only through control and attempts at relevant use. They, in turn, can be a kind of guideline or development vector, third-party experience, competition for goods, work, services, living standards and quality of life, etc. It is important to understand the fact that external factors affect the interests of all the legal relationship subjects (countries, institutional units) and territories.

The second sub-block of the model for the strategic development ensuring of the Russian economy is represented by the internal factors, which are some variables that affect Russia, which include the demographic level, emergency situations (fires, hurricanes, etc.), politics, legislative framework, technologies, culture, etc. It is worth noting that they can be influenced by stimulation through certain special measures. These factors often form and determine all national interests and opportunities, both domestically and internationally.

The third sub-block of the model for the strategic development ensuring of the Russian economy is represented by the interests of legal relationship foreign subjects, these include: maximizing profits, developing and capturing the market / markets in order to maximize profit, integration to maximize profit. It is advisable to relate to them both the activities and interests of various countries, as well as of the private foreign and international companies. It is worth noting that foreign interests are those variables that cannot be influenced, it is only possible to defend against them (protectionism of domestic business, determining the conditions for their participation in the Russian market, etc.), as well as try to cooperate with them profitably / mutually, but the realities will remain unchanged, namely their interests will be above the Russian interests. 
The fourth sub-block of the model for the strategic development ensuring of the Russian economy is represented by the interests of national subjects of legal relationship, which include: maximizing profit, developing and capturing the market / markets in order to maximize profit, integration to maximize profit. The activity of the domestic companies, on the contrary, tends to complete control, this is due to the fact that the legislator can and should establish such rules for working on the domestic market, and only after it has satisfied entering an overseas market, in which it is national interests to ensure public satisfaction and citizens in the first place.

The fifth sub-block of the model for the strategic development ensuring of the Russian economy is represented by the society interests (residents of the Russian Federation) in general and citizens (persons with Russian citizenship) in particular, these include: improving the quality and standard of living. It should be noted that it is advisable to influence (improve) them by the relevant work with internal factors.

The sixth sub-block of the model for the strategic development ensuring of the Russian economy is represented by speculative interests, they are determined by maximizing profits through usually sales and purchases, and are dictated by the group of people who have the largest financial flows, these speculative operations are usually international in nature and can be present in any markets, moreover, often veiled, it is worth noting that the central bank of the Russian Federation can fully control the speculative operations' influence only through total control, namely, their prevention or strict restrictions.

The seventh block is a sub-block of the model for the strategic development ensuring of the Russian economy with the strategic development of Russia, that is, it determines its support through the effective administrative actions, and is determined by the special criteria and indicators.

The developed and proposed model for the strategic development ensuring of the Russian economy clearly shows the factors influencing the development of Russia, the elements of its support with an emphasis on the interests of participants and the economic result.

The fifth block of the model for ensuring strategic security of the state is an area of strategic decisions with an emphasis on control, which will ensure the strategic security of the state. This block has the following subunits:

1) Relevance i.e. the usefulness of the formation, distribution and resources use, the emphasis is on the validity and rationality of these flows, as well as on the result;

2) Regulation i.e. strict adherence to iterations (systematization, standardization and unification);

3) State control (security, validity, effectiveness) i.e. monitoring the national interests' priority over the interests of institutional units is ensured by a transparent and stable state policy in relation to the activities of legal entities;

4) Market share, national interests i.e. avoidance of foreign agents and foreign interests on the markets, quotas and cultivation of national priorities and programs;

5) Tax system i.e. direct tax burden for the institutional units, the effect of fiscal policy for the state and people (through the implementation of social programs) and optimization of tax policy in general;

6) Sufficiency i.e. emphasis on this criterion in export-import operations, the idea that it is possible to export only surplus goods and import goods that are not life-supporting since they should be cultivated independently;

7) Resource Priority i.e. during depreciation and disposal, be guided by the service life and replaceability (appropriateness);

8) Investments and innovative technologies and their application (effect) i.e. strategic, tactical and operational relevance from investment and innovation; 
9) Formation, distribution, use of flows and backup system i.e. performance with an emphasis on changing resources, their justification, terms and responsible persons, for example, the creation of a reserve system (National Welfare Fund) should be formed through the side activities i.e. the activities that do not develop a country (raw material orientation), and activities that develop a country - making it competitive in the world market should be a priority, the effectiveness of government should be reduced to meeting social needs (health care, education, etc.) without the idea of getting profit in these areas (the idea of making a profit (long-term development of the country) through the efficiency of their use i.e. healthy and qualified people will bring great benefits to society), but at the expense of other areas and through the effective fiscal policy of the state;

10) The significance of a person (citizen, resources, labor) i.e. the transition from the socialist paradigms (human value is determined by his labor) and democratic (human value is determined by his income and expenses, which in turn stimulate the economy through the consumer demand and the idea of satisfying it) to a new paradigm - automation, so by replacing human labor (as physical - Robotics, as well as mental - artificial intelligence with the possibility of self-development (i.e. the algorithm is written not by a person, but by a self-developing program)) a large number of the population will stay unemployed in the next 30-40 years (cheap work will be replaced by machines, sellers will read programs information on the purchase of goods and identification of the buyer's identity, etc.) and small new highly qualified jobs (mainly completely new professions), due to their complexity and uniqueness, about $5-10 \%$ of the working population will be available, which will lead either to collapse - a new mega crisis, or will create a new paradigm human value determines humanity i.e. a person is valuable because he is and what he is (his spiritual qualities expressed in society: family man, neighbor, etc.), and to ensure his needs is a matter of the state through the new automated technologies and new mega-corporations using them;

11) Creation of a platform: result, change of resources, terms, responsible, result. So, it is the result that is responsible for the implementation and possible adjustment of the mission of the legal relationship subject, with emphasis on the current strategy, made through its strategic, tactical and operational decisions that satisfy the strategic goals and short-term performance indicators with emphasis on the plan relationship with the fact (time interval: long-term and short-term), and depending on the result, it can be either cyclical (return to analysis and repeating iterations) or modifying (goal increment, new development vector) approach, which reflects a change in development vectors with an emphasis on those responsible (for each process and subprocess be responsible, which takes resources for a certain period of time, interacts with them, is responsible for their relevant use (increment)), the direct resources themselves, and comparing the result with the resources change, answers the question of the justified and effective formation, distribution and use of the resources, therefore, it is the resources relevance, in turn, that determines their effective use, taking into account timelines and responsibilities.

Thus, it is by realizing these areas and controlling their effectiveness that the strategic security of the country as a whole and the strategic security of all legal entities in particular are ensured.

\section{Summary}

Based on the foregoing, the developed and proposed model for ensuring the strategic security of the state allows taking into account the parameters of the external and internal environment (the market of material and technical resources; the market of energy resources; the market of products and goods; the foreign exchange market; the credit market; the market for derivative financial instruments; tax policy; customs policy; 
innovation policy; other parameters of the global and national external environment that affect the activities of a particular institutional unit) with an emphasis on strategic indicators in terms of space and time, interests and priorities of legal entities (national interests and individuals and legal entities) and mechanisms (holistic systems for ensuring economic security), methods (the way of economic security) and means (through which it is realized) of the impact on them, the area of possible strategic decisions and the control itself, i.e. the resulting factor determining the creation of the platform: the result, changes in resources, terms, responsible, result and ensuring the strategic security of the state.

\section{References}

1. G.E. Krokhicheva, E.L. Arkhipov, A.S. Voskanova, Bulletin of Eurasian science 1(38) (2017)

2. O.V. Godina, Y.Y. Kosenkova, L.S. Maksimenko, Y.R. Mezentseva, T.A. Shcherbakova, Advances in Intelligent Systems and Computing 726 (2019) DOI: https://doi.org/10.1007/978-3-319-90835-9 14

3. V.V. Kayukov, A.P. Shikhverdiev, Economy of the region 14(4), 1181-1193 (2018) DOI: https://doi.org/10.17059/2018-4-10

4. E.L. Arkhipov, G.E. Krokhicheva, M.Yu. Khachaturian, Yu.A. Ax, D.V. Vakulenko, L.G. Aleksanyan, Ensuring the economic security of the regions. Certificate of state registration of the database No. 2019622469 of December 24, 2019. Official Bulletin of the Federal Service for Intellectual Property, Patents and Trademarks. Computer programs for the topology database of integrated circuits (Moscow, FGU FIPS, 2019)

5. On the Economic Security Strategy of the Russian Federation for the period until 2030: Decree of the President of the Russian Federation of 13.05.2017 N 208, http://www.consultant.ru/document/cons_doc_LAW_216629/1d8dcf5824d 5241136fa09b9e9c672ac5d325365/

6. A.G. Svetlakov, I.M. Swallow, Economy of the region 14(2), 474-484 (2018) DOI: https://doi.org/10.17059/2018-2-11

7. On national goals and strategic objectives of the development of the Russian Federation for the period until 2024: Decree of the President of the Russian Federation from 07.05.2018 № 204, http://www.consultant.ru/document/cons_doc_LAW_297432/

8. S.V. Novoselov, S.A. Panikhidnikov, Systematic assessment of the economic security of the region Coal 12(1113) (2018) DOI: http://dx.doi.org/10.18796/0041-5790-2018$12-48-53$

9. T.L. Sergeeva, L.E. Skripkina, Bulletin of Novgorod State University 87(2), 97-100 (2015)

10. E.A. Bessonova, O.Yu. Mereshchenko, Questions of the regional economy 29(4), 1724 (2016)

11. E.A. Dynnikov, A.N. Milyukin, Materials of the IV International Scientific and Practical Conference dedicated to the 140th anniversary of the founding of Belgorod State University, 95-98 (2016)

12. E.V. Mikhalkina, N.A. Kosolapova, 2018 Space of Economics 1 DOI: https://doi.org/10.23683/2073-6606-2018-16-1-118-133

13. V.A. Tsvetkov, M.N. Dudin, N.V. Lyasnikov, Analytical approaches and methods for assessing the economic security of a region Regional Economy 15(1), 1-12 (2019) DOI: https://doi.org/10.17059/2019-1-1 
14. O.A. Lomovtseva, Scientific Bulletin of the Belgorod State University. Series: Economics. Informatics 1-1(120) (2012) https://cyberleninka.ru/article/n/sovokupnyyresursnyy-potentsial-regiona-metodologiya-opredeleniya-i-izmereniya

15. Liu Chunguang, J.R. Mezentseva, G.E. Krokhicheva, E.L. Arkhipov, O.A. Alekseeva, Advances in Economics, Business and Management Research 139, 240-247 DOI https://doi.org/10.2991/aebmr.k.200509.044 